\title{
To sleep or not to sleep during deep brain stimulation surgery for Parkinson disease?
}

Tipu Z. Aziz, FMedSci

Marwan Hariz, MD, PhD

Correspondence to

T.Z. Aziz:

tipu.aziz@nds.ox.ac.uk

Neurology ${ }^{\circledR} 2017 ; 89: 1-2$
In functional stereotactic neurosurgery, precise placement of lesions or deep brain stimulation (DBS) electrodes is paramount. From the beginning of the specialty, electrical stimulation of the brain target prior to lesioning, and confirmation of accuracy of targeting by postoperative imaging, have been critical. ${ }^{1}$ Two schools subsequently evolved: one using macroelectrode stimulation in the awake patient with careful on-table assessment and one using microelectrode recording (MER) to map out boundaries of the target followed by microstimulation to assess efficacy and avoid side effects. For many, the latter technique was adopted as the gold standard, but the evidence to support the superior efficacy or better safety of this stance was lacking. ${ }^{2}$

In this issue of $N e u r o l o g y{ }^{\circledR}$, Brodsky et al. ${ }^{3}$ analyze the 6-month outcome of 30 patients who underwent asleep DBS without MER but with intraoperative imaging verification of targeting accuracy, compared to 39 who underwent awake MER-guided DBS. In the asleep DBS group, 7 were implanted in the subthalamic nucleus (STN) and 23 in the globus pallidus pars interna (GPi). In the awake MER-guided DBS group. 18 were in STN and 21 in GPi. The asleep patients had intraoperative CT scan to verify the electrode location. The improvement was the same in both groups concerning Unified Parkinson's Disease Rating Scale (UPDRS) III as well as UPDRS II and "on" time without dyskinesias. The improvement in the summary index of the 39-item Parkinson's Disease Questionnaire, and in subscores for cognition and communication, were better in the asleep DBS group. The outcome of speech was also better in the asleep than in the awake group. The authors concluded that asleep DBS improves motor outcome similar to, or better than, awake DBS.

A possible limitation of this study is that the groups of awake and asleep patients were not randomized and the comparison was between a historical cohort of patients who had DBS surgery awake with a more recent cohort who had surgery asleep. However, as the authors pointed out, it would have been difficult to recruit patients in order to randomize between awake and asleep. On the other hand, the strength of this study is that it reflects the experience of a single center and a single neurosurgeon: to add to the importance of this article, it is worth noting that the surgeon is one of the pioneers and a proponent of MER in North America and in 2004 edited a comprehensive book to that effect. ${ }^{4}$

In that book, the senior editor asked the following:

1. Does MER add demonstrable value to movement disorder surgery?

2. Does MER add risk to movement disorder surgery, and if so, what is the risk/benefit ratio?

Now, 13 years later, the article at hand by the same author answers the first question above: MER did not add demonstrable value to movement disorders surgery.

As for the second question, the authors discuss the wealth of data available in the literature showing that MER may increase the risk of hemorrhage compared to functional stereotactic neurosurgery-whether ablative procedure or DBS-performed without MER. ${ }^{5,6}$ Furthermore, the costs with MER surgery are higher. ${ }^{7}$ Finally, the use of MER in awake patients may not be a sufficient guarantee for an accurate placement of the DBS electrode in the intended brain target: in a recent publication, looking at Medicare and National Surgical Quality Improvement Program records of 28,179 DBS procedures, with MER guidance, revision rates for implants could vary from $15.2 \%$ to $34 \% .{ }^{8}$ On the other hand, immediate intraoperative or postoperative stereotactic imaging does provide the means to verify that the DBS electrode has indeed reached the intended target.

The role of stereotactic imaging. Regardless of MERawake DBS or non-MER asleep DBS, the most important verdict as to the accuracy of stereotactic targeting is the verification of hitting the targeted structure. The advances in MRI in the last decade have enabled visualization of the STN and the GPi in an individual patient, obviating the need for an atlas. Before these advances were made, radiologic stereotactic guidance was not altogether reliable (due to 
MRI distortion problems and CT visualization shortcomings) and therefore MER was necessary. The ongoing need for MER is also questionable with additional advances in image fusion algorithms. Availability of either an MRI machine or a dedicated CT machine in the operating room have made it possible to perform stereotactic imaging immediately after placement of the electrodes to verify the accuracy of targeting in the operating room, ensuring targeting accuracy before the surgery is finished. Hence, if the target can be readily visualized on stereotactic MRI and if the DBS electrodes - in relation to the targetcan also be readily visualized on imaging in stereotactic space, and of course if the surgeon is confident in stereotactic functional neurosurgery and in detailed anatomy of the target structure and its surroundings, why would there be a need for awake surgery, with or without MER?

The second question is, if one can perform accurate electrode placement and verify the targeting accuracy on imaging alone, does the patient need to be awake?

Eliminating MER will reduce risks without compromising outcomes, shorten the procedure duration, and reduce its costs. Asleep surgery is certainly better for patients, who will not need to be "off" medications for several hours prior to, and several hours during, the surgery. ${ }^{9}$ In fact, asleep DBS, provided experience in modern stereotactic imaging, both before and especially immediately after the procedure, is gaining momentum even in centers that previously used MER-awake DBS surgery. ${ }^{10}$ However, performing surgery in asleep patients precludes the ability to determine clinical benefit/side effects from macrostimulation and therefore somewhat tempers adoption of asleep surgery in even the best circumstances (for example, with an intraoperative MRI suite).

Thus the following question arises: Is there a gold standard and is it the use of MER and awake DBS surgery? The modern gold standard of DBS surgery seems to be more a confirmation of electrode placement before the procedure is finished, whatever technique and whatever mode of anesthesia is used. MER would thus be reserved to where it best belongs: as a tool for scientific research on basal ganglia neuronal activity.

\section{STUDY FUNDING}

No targeted funding reported.

\section{DISCLOSURE}

T. Aziz has received honoraria and travel expenses from Medtronic, Boston Scientific, and Abbott for lectures. T. Aziz and Oxford Functional Neurosurgery are supported by the Oxford Biomedical Research Centre (NIHR), Charles Wolfson Charitable Trust, The Norman Collisson Foundation, and the Placito Bequest. M. Hariz has received honoraria and travel expenses from Medtronic and Boston Scientific for speaking at meetings. M. Hariz and the Unit of Functional Neurosurgery are supported by the Parkinson Appeal UK and the Monument Trust. Go to Neurology.org for full disclosures.

\section{REFERENCES}

1. Spiegel EA, Wycis HT. Thalamotomy and pallidotomy for treatment of choreic movements. Acta Neurochirurgica 1952;2:417-422.

2. Hariz MI, Fodstad H. Do microelectrode techniques increase accuracy or decrease risks in pallidotomy and deep brain stimulation? A critical review of the literature. Stereotact Funct Neurosurg 1999;72:157-169.

3. Brodsky MA, Anderson S, Murchison C, et al. Clinical outcomes of asleep vs awake deep brain stimulation for Parkinson disease. Neurology 2017;89:xxx-xx.

4. Israel Z, Burchiel KJ, eds. Microelectrode Recording in Movement Disorder Surgery. New York: Thieme; 2004.

5. Zrinzo L, Foltynie T, Limousin P, Hariz M. Reducing hemorrhagic complications in functional neurosurgery: a large case series and systematic literature review. J Neurosurg 2012;116:84-94.

6. Carroll CB, Scott R, Davies LE, Aziz T. The pallidotomy debate. Br J Neurosurg 1998;12:146-150.

7. McClelland S. A cost analysis of intraoperative microelectrode recording during subthalamic stimulation for Parkinson's disease. Mov Disord 2001;26:1422-1427.

8. Rolston JD, Englot DJ, Starr PA, Larson PS. An unexpectedly high rate of revisions and removals in deep brain stimulation surgery: analysis of multiple databases. Parkinsonism Relat Disord 2016;33:72-77.

9. LaHue SC, Ostrem JL, Galifianakis NB, et al. Parkinson's disease patient preference and experience with various methods of DBS lead placement. Parkinsonism Relat Disord 2017;41:25-30.

10. Chen T, Mirzadeh Z, Ponce FA. "Asleep” deep brain stimulation surgery: a critical review of the literature. World Neurosurg 2017;105:191-198. 


\section{Neurology}

\section{To sleep or not to sleep during deep brain stimulation surgery for Parkinson disease?}

Tipu Z. Aziz and Marwan Hariz

Neurology published online October 6, 2017

DOI 10.1212/WNL.0000000000004635

This information is current as of October 6, 2017
Updated Information \&
including high resolution figures, can be found at:
Services 004635.full.html
Permissions \& Licensing
Information about reproducing this article in parts (figures,tables) or in its entirety can be found online at:
http://www.neurology.org/misc/about.xhtml\#permissions
Reprints
Information about ordering reprints can be found online:
http://www.neurology.org/misc/addir.xhtml\#reprintsus

http://www.neurology.org/content/early/2017/10/06/WNL.0000000000

Neurology ${ }^{\circledR}$ is the official journal of the American Academy of Neurology. Published continuously since 1951, it is now a weekly with 48 issues per year. Copyright (O 2017 American Academy of Neurology. All rights reserved. Print ISSN: 0028-3878. Online ISSN: 1526-632X.

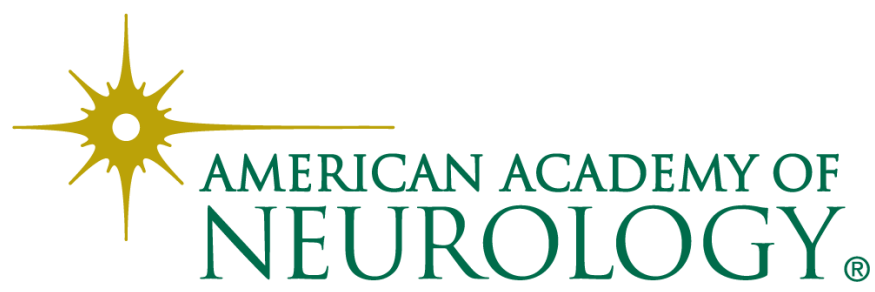

